\title{
Diel patterns of migration, feeding, and spawning by salps in the subarctic Pacific
}

\author{
Jennifer E. Purcell ${ }^{1}$, Laurence P. Madin ${ }^{2}$ \\ ${ }^{1}$ Horn Point Environmental Laboratories, PO Box 775 Cambridge, Maryland 21613, USA \\ ${ }^{2}$ Woods Hole Oceanographic Institution, Woods Hole, Massachusetts 02543, USA
}

\begin{abstract}
The common pattern of feeding in marine zooplankton undergoing diel vertical migrations is an alternation between not feeding at depth during the day and feeding near the surface at night. In contrast to this pattern, the pelagic tunicate Cyclosalpa bakeri fed actively during the day at depths of 30 to $60 \mathrm{~m}$, but ceased to feed after nighttime migration into the surface layer $(<30 \mathrm{~m})$. The cessation of feeding at night cannot be explained satisfactorily by current hypotheses that vertical migration serves to reduce visual predation, minimize photodamage, promote dispersion, reduce metabolic costs, or increase fecundity. We offer evidence that the feeding and migration pattern of $C$. bakeri is related to their reproductive behavior. Our data suggest that their nighttime ascent acts to concentrate the salps near the surface where spawning occurs, and filter-feeding ceases so that the swimming sperm are not trapped and ingested before they can enter the oviduct.
\end{abstract}

\section{INTRODUCTION}

Diel vertical migration is a common phenomenon among fish and invertebrates in marine and freshwater ecosystems, and there has been a great deal of speculation about the evolutionary advantages of migration (recently reviewed by Kerfoot 1985, Bayly 1986, Haney 1988, Lampert 1989). The various hypothesized advantages of vertical migration were developed mainly from studies on herbivorous crustacean zooplankton that rest at daytime depths and feed in surface waters at night, and on their fish predators. A few recent studies show that some zooplankton with non-visual predators display reversed migration (nocturnal descent), and that migration may be under behavioral or genetic control (e.g. Neill 1990, Ohman 1990).

Salps are often important suspension feeders in the oceans because of their large size and high filtering rates, as compared with other planktonic grazers (Alldredge \& Madin 1982). Salps swim continuously, and pump water through a mucous net that fills the entire pharyngeal cavity. The net is secreted at the anterior end and consumed at the posterior esophagus, along with all trapped particulate material (Madin 1974). Often the mucous net can retain some particles as small as $1.0 \mu \mathrm{m}$, and filters $100 \%$ of particles larger than about $4 \mu \mathrm{m}$ from all the water that passes through the salp (Harbison \& McAlister 1979, Caron et al. 1989). Of the 40 species of salp that are widely distributed in temperate and tropical regions, relatively few have been shown to vertically migrate (Franqueville 1971, Harbison \& Campenot 1979, Wiebe et al. 1979).

The reproductive cycle of salps is an alternation between an asexually reproducing solitary generation and a sexually reproducing aggregate generation in which individuals are connected together in whorls or chains (Alldredge \& Madin 1982). The aggregate salps are protogynous hermaphrodites; usually each individual has 1 implanted ovum. Sperm are shed into the water, but fertilization of the egg is internal. To reach the egg, sperm must enter a fertilization duct which opens into the atrial (feeding) chamber of the salp. During development of the embryo, the parent aggregate salp becomes a functional male, releasing sperm into the water for the fertilization of other, younger aggregates.

Surface observations and net collections made during a cruise to Station $\mathrm{P}\left(50^{\circ} \mathrm{N}, 145^{\circ} \mathrm{W}\right)$ in the subarctic Pacific as part of the Subarctic Pacific Ecosystem Research (SUPER) project revealed a shallow vertical migration by large numbers of the salp Cyclosalpa bakeri Ritter, 1905 (Miller \& SUPER Group 1988). During our research in 1987 and 1988 on the grazing impact of C. bakeri on the phytoplankton at Station $\mathrm{P}$, we discovered that feeding rates, as reflected by gut contents, were dramatically lower at night, when salps 
were at the surface, than in the day when they were at depth. This is contrary to the usual behavior of vertically migrating marine zooplankton, which typically begin feeding when they arrive in surface waters after dark (e.g. Roman et al. 1988, Dagg et al. 1989). In this paper we document the salps' diel vertical distribution and feeding pattern, and discuss these behaviors as related to hypothesized advantages of vertical migration by zooplankton.

\section{MATERIALS AND METHODS}

The abundance of Cyclosalpa bakeri was measured at Station $P$ in the subarctic Pacific using an openingclosing MOCNESS net system with a $1 \mathrm{~m}^{2}$ mouth area and $243 \mu \mathrm{m}$ mesh nets. The nets took samples over 8 depth intervals, which were selected based on hydrographic data, between 0 and $200 \mathrm{~m}$. Towing speed was 1.8 to 2 knots. The mean volume filtered in 26 tows containing C. bakeri was $133 \mathrm{~m}^{3} \pm 53$ (SD). One set of tows was made during both day and night on 3 accasions (10-11, 13-14, and 24-26 August 1988). These samples were preserved in $10 \%$ buffered formalin, and the salps were counted and measured in the laboratory. To test for vertical migration of salps, we standardized the total number of salps per $\mathrm{m}^{2}$ to 100 for each net series. This corrected for the sensitivity of chi-square tests to small numbers (D. Jacobs pers. comm.). We then compared the proportions of salps above and below the thermocline during day and night in a $2 \times 2$ contingency table.

Vertical profiles of temperature, salinity, and water samples were taken at $10 \mathrm{~m}$ intervals with a CTD before and after each net series. The water samples were centrifuged, and the pigments extracted from the residue in $60 / 40$ acetone/DMSO (dimethyl sulfoxide). Total phytoplankton pigment concentration (chlorophyll and phaeophytin) was measured by fluorescence using a Turner 112 Fluorometer calibrated against a spectrophotometer using a chlorophyll extract of mixed phytoplankton.

Salps were collected in jars by divers during 10 SCUBA dives in September 1987, and 13 dives in August 1988, at Station P. The stomach contents of these salps were measured by allowing the salps to evacuate their guts in the collecting jar, and then collecting the fecal material by pipette. Gut evacuation was usually complete in less than 2 h at $11 \pm 1^{\circ} \mathrm{C}$. This material was centrifuged, and the residue extracted in $90 \%$ acetone (in 1987) or 60/40 acetone/DMSO (in 1988). Chlorophyll and phaeophytin concentrations in the fecal material were measured by fluorescence (Madin \& Cetta 1984) as above.

Salp length between the oral and atrial openings was measured to the nearest millimeter with a ruler. Usually only 1 member of an aggregate whorl was measured, and the number of individuals in the whorl counted. Aggregate salps ranged from 10 to $50 \mathrm{~mm}$ in length, with 7 to 13 individuals per whorl. Solitary salps were 40 to $100 \mathrm{~mm}$ in length. Some salps spanning the observed size range were dried at $60^{\circ} \mathrm{C}$ for at least $2 \mathrm{~d}$ and stored in a dessicator. On shore, they were redried, weighed, and combusted in a Control Equipment 240 CHN analyser. Regressions of length to carbon content were determined in both years and used to normalize gut contents to body carbon weights (Madin \& Purcell unpubl.).

In order to determine if the salps were actively feeding during day and night in situ, divers squirted a suspension of carmine particles in seawater into the incurrent opening of swimming salps (Madin 1974). If the feeding net was present, the carmine was retained and made the net visible; divers used flashlights at night.

We attempted to assess the readiness of aggregategeneration salps to spawn at several times of day and night by examining their testes for the presence of motile sperm under 40 to $100 \times$ magnification. We also preserved specimens in formalin during the day and night for later microscopic examination of the testes.

\section{RESULTS}

Populations of Cyclosalpa bakeri in the subarctic Pacific exhibited a shallow vertical migration. MOCNESS tows in August 1988 allowed us to compare day and night vertical distributions of the salps (Fig. 1a). Salps occurred mostly within the thermocline (30 to $60 \mathrm{~m}$ ) during the day, and above it $(<30 \mathrm{~m})$ at night. Salps were concentrated at the top of the thermocline on all days, and at the surface at night on 24-26 August and to a lesser extent on 13-14 August (Figs. 1a \& 2). Although salps on 2 occasions were as concentrated at depth during daytime as they were at the surface at night, the pattern observed on our SCUBA dives, as well as on 2 sampling dates, was one of movement into the upper $20 \mathrm{~m}$ at dusk. Significantly more salps occurred above the thermocline at night than during the day on 24-26 August and on 10-11 August ( $p \ll 0.001$ ), but not on 13-14 August. On SCUBA dives in August 1988, we observed that salps were concentrated within the thermocline around midday and in the surface $20 \mathrm{~m}$ around midnight. Their ascent began before darkness, and their descent was completed after surnise (see Fig. 3 for dive times).

The differences in day and night distributions did not correspond to any differences in the hydrographic parameters (Fig. 1b). Depth profiles of temperature, 

(26 August) and night (24 August) depth distributions of salps (no. $\mathrm{m}^{-3}$ ) in the subarctic Pacific in 1988. (b) Vertical profiles of total phytoplankton pigment concentration, temperature, and salinity taken after each net series $112: 00$ $\mathrm{h}$ on 26 August and $00: 30 \mathrm{~h}$ on 25 August)
Fig. 1. Cyclosalpa bakeri. (a) Day
Day (10:00)

\section{a}

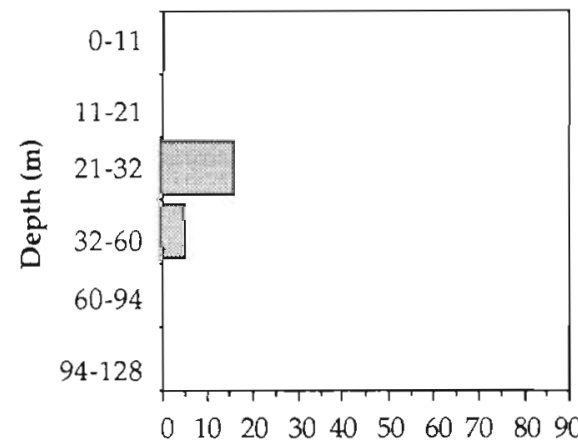

Night (23:00)

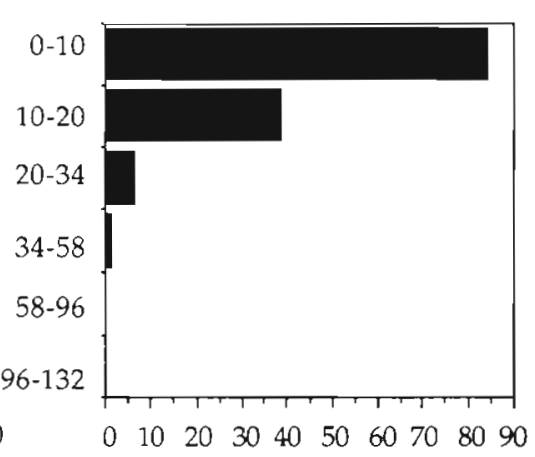

Salp Abundance $\left(\# / \mathrm{m}^{3}\right)$

\section{b}

Total Pigment $\left(\mathrm{mg} / \mathrm{m}^{3}\right)$

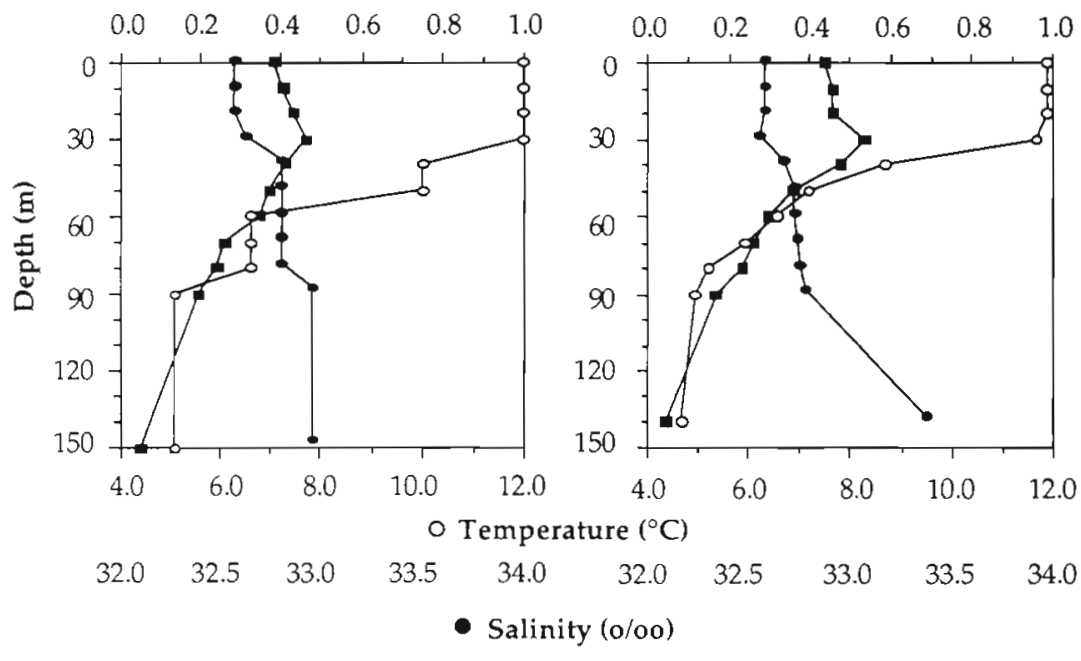

salinity, and phytoplankton pigment concentration remained essentially constant throughout each sampling period, and the profiles were similar on all dates. During daylight hours in 1988, the greatest density of salps and of phytoplankton pigment concentrations occurred at the same depth (Fig. 1a, b). The persistent subsurface peak in total phytoplankton pigments was due to increased phaeopigment (not shown) around the top of the thermocline, which may have resulted from salps defecating there. In 1987, total pigment concentrations were very similar above the thermocline, and no peak was observed at the salps daytime depth.

The body wall and gut of Cyclosalpa bakeri are transparent, and divers observed that all of the dozens of salps seen in the daytime had visibly full guts, but that guts were empty or only partially full at night. All 49 salps tested with carmine particles on dives between 06:00 and 20:50 h had mucous feeding nets in place, but only 18 of 20 salps tested at $22: 15 \mathrm{~h}$ and 13 of 21 salps tested at $04: 30 \mathrm{~h}$ had feeding nets. Thus it appears that the salps stopped feeding for at least part of the time during which they were near the surface at night.

Salps collected at depth in the daytime had more food in their guts than those collected near the surface at night. Average values of weight-specific gut pigment content per dive are shown in Fig. 3, plotted against time of day. The ratio of day:night mean values for weight-specific gut pigment content was greater for aggregate-generation salps (11.7 in 1987, 2.9 in 1988) than for solitaries (3.7 in 1987, 2.0 in 1988). More detailed comparisons of gut content data for salps showed significant day-night differences in 4 out of 5 pairs of consecutive dives in 1987 and 6 of 9 pairs of dives in 1988 (Table 1). By contrast, day-night differences in the available food, expressed as the ratios of pigment concentration at the depths where salps were collected by day and night, were negligible (Table 1).

We observed motile sperm from the testes of aggregate-generation Cyclosalpa bakeri at night (05:30 h), 
a

Day (11:00)

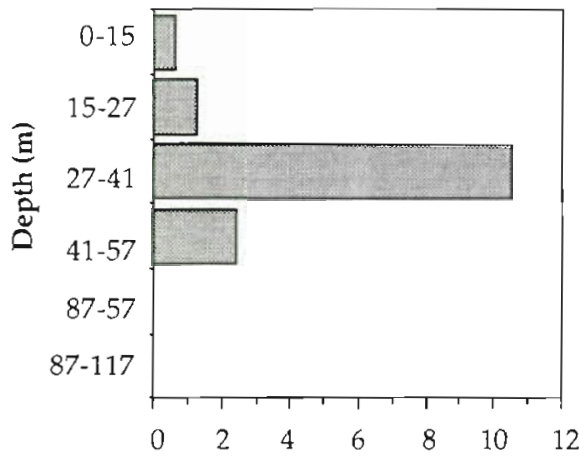

Night (23:00)

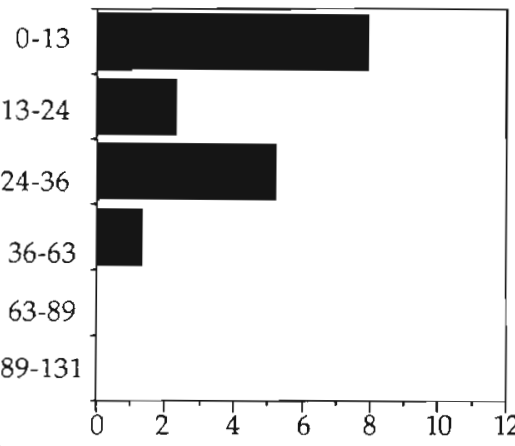

Salp Abundance $\left(\# / \mathrm{m}^{3}\right)$

\section{b}
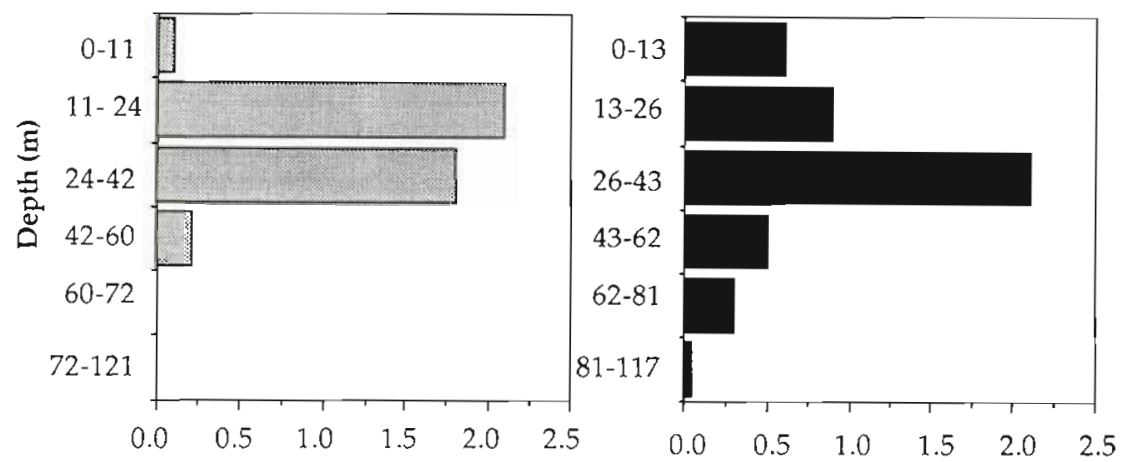

Salp Abundance $\left(\# / \mathrm{m}^{3}\right)$

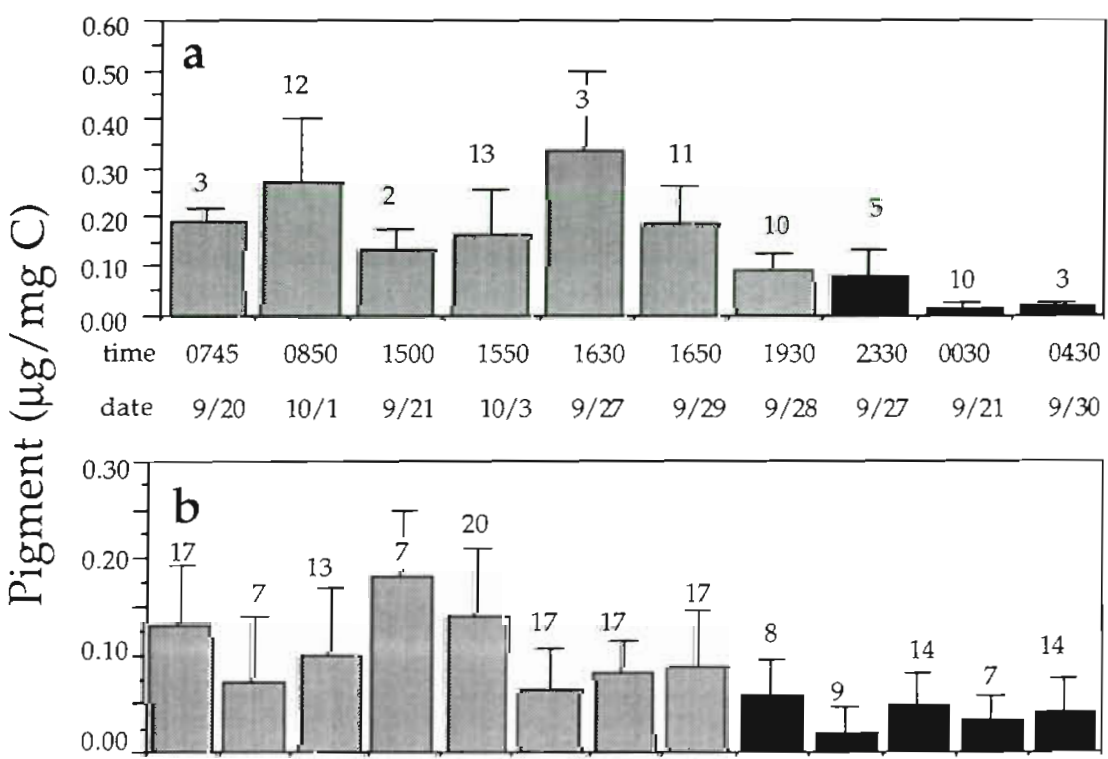

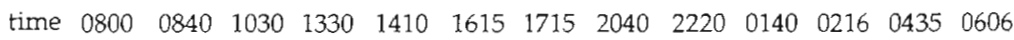

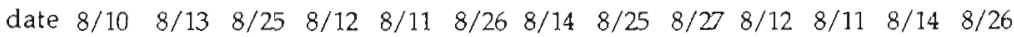

Time and Date of Collection
Fig. 2. Cyclosalpa bakeri. Day and night depth distributions of saips in the subarctic Pacific on (a) 10-11 August 1988, and (b) 13-14 August 1988
Fig. 3. Cyclosalpa bakeri. Day and night gut pigment content (means \pm 1 standard deviation) of salps in (a) September and October 1987 and (b) August 1988. Numbers of samples analysed appear above the bars 
Table 1. Cyclosalpa bakeri. Day:night ratios of the mean weight-specific gut contents of salps, and of in situ phytoplankton pigment concentrations at the dive depths for consecutive day and night dives in the subarctic Pacific. See Fig. 3 for times of dives. Day and night gut contents of individual salps were compared in the dive pairs (1-way ANOVA); statistical significance indicated as $\cdot p<0.05, \cdots p<0.005$, $\cdots p<0.001$

\begin{tabular}{|ccc|}
\hline Dates of dive pairs & $\begin{array}{c}\text { Ratio of } \\
\text { day:night gut } \\
\text { contents }\end{array}$ & $\begin{array}{c}\text { Ratio of } \\
\text { day:night } \\
\text { pigment in situ }\end{array}$ \\
\hline 198721,21 Sep & $14.9 \cdots$ & 1.0 \\
27,27 Sep & $4.2^{\circ}$ & 0.8 \\
27,28 Sep & 1.2 & 1.0 \\
29,30 Sep & $10.8 \cdots$ & 1.2 \\
30 Sep, 1 Oct & $14.8 \cdots$ & 1.2 \\
1988 10, 11 Aug & $2.8 \cdots$ & 0.8 \\
11,11 Aug & $2.9 \cdots$ & 1.0 \\
11,12 Aug & $6.7 \cdots$ & 1.1 \\
12,12 Aug & $8.6 \cdots$ & 1.0 \\
13,14 Aug & 2.2 & 1.1 \\
14,14 Aug & $2.6 \cdots$ & 0.9 \\
25,26 Aug & $2.0 \cdots$ & 1.0 \\
26,26 Aug & 1.0 & 1.0 \\
26,27 Aug & 1.0 & 1.2 \\
\hline
\end{tabular}

but not during the day or evening (16:30 and 20:00 h). This evidence suggests that the salps release sperm near the surface during the late night or early morning hours. We were not able to tell if salps were releasing sperm in situ. Examination of preserved testes did not indicate whether the salps were ready to release sperm or had recently spawned.

\section{DISCUSSION}

An explanation of the migration of Cyclosalpa bakeri should address 3 questions: (1) Why do the salps reside at depth during the day? (2) Why do the salps move from within the thermocline to the surface at night? (3) Why do they stop feeding in surface waters? Our data directly address only the third question; however, we also briefly consider the first 2 questions as they relate to hypotheses on the advantages of vertical migration.

Most of these hypotheses were originally conceived to explain why animals leave surface waters during the day. The beginning assumption is that it is preferable to be in surface waters because of higher food densities and higher temperatures, and that other factors force zooplankton to move into deeper waters during the day. Murray \& Hjort (1912) first proposed that daytime migration out of well-lit surface waters to the lower light levels of greater depths reduces mortality due to visual predators. The considerable evidence now avail- able to support this hypothesis comes mainly from crustacean zooplankton (e.g. recent reviews, and Bollens \& Frost 1989). The importance of non-visual predation has been documented as a driving force for reverse vertical migration (Ohman et al. 1983, Ohman 1990, Neill 1990)

Kashkina (1986) lists 47 species of fish in 10 orders that are known to feed on salps. Species within several of these orders, including salmonids, clupeids and myctophids, occur in the eastern North Pacific (J. Craddock pers. comm.). Because of its transparency, Cyclosalpa bakeri is probably fairly cryptic to visual predators (McFall-Ngai 1990), and their daytime descent would further reduce their visibility. We did not sample for visual predators at Station $P$, so we cannot assess potential predation pressures on salps. Nor do we have data for other hypotheses on daytime descent, such as avoidance of damage from short-wavelength radiation (Hairston 1976), or improved utilization of phytoplankton production (Enright 1977). We cannot eliminate these explanations for the daytime descent of C. bakeri in the subarctic Pacific.

Some non-visual predators (ctenophores, siphonophores, medusae, amphipods) feed on salps in both surface and deep water (Madin \& Harbison 1977, Purcell 1981, Diebel 1988, Madin 1988, Larson et al. 1989). We collected 1 narcomedusa (Cunina sp.) with salp remains in its stomach, but this species was uncommon in the MOCNESS samples. Non-visual predators are reported to cause nocturnal descent of zooplankton, not daytime dscent as in Cyclosalpa bakeri (Ohman et al. 1983).

A recent re-examination of the hypotheses (McLaren 1963 , 1974) that migration to colder, deeper waters could offer metabolic or demographic advantages has shown no benefits to copepods (Ohman 1990). The potential metabolic advantage could be large for a species like Salpa aspera, which migrates over $800 \mathrm{~m}$ and through a temperature range of $20^{\circ} \mathrm{C}$ (Wiebe et al. 1979). For Cyclosalpa bakeri, however, which migrates through a temperature range of less than $5^{\circ} \mathrm{C}$, any possible metabolic and demographic advantages would be small. In any case, these hypotheses do not offer an explanation of the timing of the migration.

The vertical excursion of Cyclosalpa bakeri did not move salps between water masses in the subarctic Pacific (T. Powell pers. comm.); therefore, the idea that migration moves populations of zooplankton between vertically stratified water masses, affecting dispersion and feeding success (Hardy 1935, Miller 1970), cannot apply in this case.

A hypothesis that has received little attention proposes a reason for nocturnal ascent. Wynne-Edwards (1962) suggested that populations that are dispersed for feeding need a mechanism that periodically concen- 
trates them for social interactions, such as courtship or spawning. In particular, the combined effects of population concentration at the air-water interface and synchronization of spawning would increase the frequency of fertilization. These surface concentrations may occur at night because visual predation on the spawners would be reduced in darkness.

Many species of marine fish and invertebrates aggregate and spawn at night (reviewed in Lobel 1978 and Giese \& Kanatani 1987). The salps Salpa aspera and $S$. fusiformis perform long vertical migrations and can be extremely dense when concentrated at the surface at night (Franqueville 1971, Wiebe et al. 1979). The salp Thalia democratica in Australia swarms at the surface at night, and gives birth to embryos synchronously at about 08:00 h (Heron 1972), suggesting a prior synchrony of fertilization. Spawning recently was observed in these aggregations just before dawn (R. L Miller pers. comm.). Our observations of motile sperm. in the testes of Cyclosalpa bakeri at night, but not during the day, support the possibility that this species spawns near the surface at night. While there are few data on the feeding or spawning behavior of salps at night, it appears that nighttime aggregation and spawning may occur in several species.

Change in light intensity is considered to be the major environmental cue for migration in other zooplankton (reviewed in Haney 1988). Light does affect the swimming behavior of salps. In laboratory experiments, swimming activity of some species increased as light intensity diminished, and vice versa (Mackie \& Bone 1977), but other species appeared to swim toward light sources (Madin 1990). The implication of these observations for the behavior of salps in the sea is still unclear. Changes in light intensity trigger both spawning and vertical swimming patterns in some hydromedusae (Miller 1979, Mills 1983, Mills \& Goy 1988). Spawning in several other marine invertebrates, including 2 species of benthic tunicates, is triggered by changes in light, and sometimes is correlated with the lunar cycle (reviewed in Giese \& Kanatani 1987).

Light may be involved in synchronizing migration and spawning in Cyclosalpa bakeri. The highest concentration sampled ( $>80$ salps $\mathrm{m}^{-3}$ ) occurred at the full moon on 24 August (Fig. 1a). Salps were more dispersed on the nights of 10 and 14 August, which were near the time of the new moon on 12 August. These results suggest that migration, and/or spawning, in C. bakeri may be related to the lunar cycle.

Finally, we need an explanation for the cessation of feeding in Cyclosalpa bakeri. Fertilization of the ova contained within the female-stage aggregate salps requires that sperm shed into the water by male-stage aggregates enter the oviduct, which opens into the atrial chamber behind the feeding net. Only the sperm of Thalia democratica have been measured; they are $58 \mu \mathrm{m}$ long and $0.8 \mu \mathrm{m}$ in diameter (Holland 1988). If the sperm of $C$. bakeri are of similar size, they would probably be trapped in the mucous feeding net before reaching the oviduct if the salps were feeding. In order to allow sperm to reach the eggs, the female-stage aggregate salps must stop feeding. It should not be necessary for the male-stage (fertilized) salps or the asexually reproducing solitary salps to stop feeding, although their filtering could reduce the number of sperm in the water. Consistent with this biological distinction, our data showed a greater difference between day and night gut contents for the aggregates than for the solitaries. In summary, our observations support the hypothesis that the diel cycles of feeding activity and vertical migration are related to the reproductive behavior of $C$. bakeri.

Acknowledgements. We thank Charlie B. Miller for organizing the SUPER cruises and making the MOCNESS collections F. Cresswell counted the plankton samples and S. Hacker prepared the figures. We are grateful for statistical advice from D. Jacobs and comments on the manuscript by Carolyn A. Miller. The research was supported by grants from the National Science Foundation (OCE-8614201 and OCE8700776) to J. E. P. and L. P. M. as part of the Subarctic Pacific Ecosystem Research program. UMCEES Contribution No. 2216 and WHOI Contribution No. 7351.

\section{LITERATURE CITED}

Alldredge, A. L., Madin, L. P. (1982). Pelagic tunicates: unique herbivores in the marine plankton. BioSci. 32: 655-663

Bayly, I. A. E. (1986). Aspects of diel vertical migration and its enigma variations. In: DeDeckker, P., Williams, W D. (eds.) Monographiae biological, Vol. 61 Dr. W. Junk, Amsterdam, p. 349-368

Bollens, S. M., Frost, B. W. (1989). Zooplanktivorous fish and variable diel vertical migration in the marine planktonic copepod Calanus pacificus. Limnol. Oceanogr. 34: 1072-1083

Caron, D. A., Madin, L. P., Cole, J. J. (1989). Composition and degradation of salp fecal pellets: implications for vertical flux in oceanic environments. J. mar Res. 47. 829-850

Dagg, M. L., Frost, B. W., Walser, Jr., W E. (1989). Copepod diel migration, feeding, and the vertical flux of pheopigmnts. Limnol. Oceanogr 34: 1062-1071

Diebel, C. (1988). Observations on the anatomy and behavior of Phronima sedentaria (Forskal) (Amphipoda: Hyperiidea). J. crust. B10l. 81. 79--90

Enright, J. T (1977). Diurnal vertical migration: adaptive significance and timing. Part 1. Selective advantage: a metabolic model. Limnol. Oceanogr 22: 856-886

Franqueville, C. (1971). Macroplancton profond (Invertebres) de la Mediterranée nord-occidentale. Téthys 3: 11-55

Giese, A. C., Kanatani, H. (1987). Maturation and spawning. In: Giese, A. C., Pearse, J. S., Pearse, V. B. (eds.) Reproduction of marine invertebrates, Vol. IX. General aspects: seeking unity in diversity. Blackwell Scientific Publications, Palo Alto, p. 251-329

Hairston, N. G. (1976). Photoprotection by carotenoid pig- 
ments in the copepod Diaptomus nevadensis. Proc. natl Acad. Sci. U.S.A. 73: 971-974

Haney, J. F. (1988). Diel patterns of zooplankton behavior Bull. mar. Sci. 43: 583-603

Harbison, G. R., Campenot, R. B. (1979). Effects of temperature on the swimming of salps (Tunicata, Thaliacea): implications for vertical migration. Limnol. Oceanogr 24 1081-1091

Harbison, G. R., McAlister, V L. (1979). The filter-feeding rates and particle retention efficiencies of three species of Cyclosalpa (Tunicata, Thaliacea). Limnol. Oceanogr. 24 $875-892$

Hardy, A. C. (1935). The plankton community, the whale fisheries, and the hypothesis of animal exclusion. 'Discovery' Rep. 11: 273-370

Heron, A. C. (1972). Population ecology of a colonizing species: the pelagic tunicate Thalia democratica 2. Population growth rate. Oecologia 10: 294-312

Holland, L. Z. (1988). Spermatogenesis in a salp Thalia democratica (Tunicata: Thaliacea): an electron microscopic study. J. Morph. 198: 189-204

Kashkina, A. A. (1986). Feeding of fishes on salps (Tunicata, Thaliacea). J Ichthyol. (USSR) 26:57-64

Kerfoot, W C. (1985). Adaptive value of vertical migration: comments on the predation hypothesis and some alternatives. Contrib. mar. Sci. Univ. Tex. 28: 91-113

Lampert, $W$. (1989). The adaptive significance of diel vertical migration. Funct. Ecol. 3: 21-27

Larson, R. J., Mills, C. E., Harbison, G. R. (1989). In situ foraging and feeding behaviour of narcomedusae (Cnidaria: Hydrozoa). J. mar biol. Ass. U.K. 69: 785-794

Lobel, P. S. (1978). Diel, lunar, and seasonal periodicity in the reproductive behavior of the pomacanthid fish Centropyge potteri, and some other reef fishes in Hawaii. Pacif. Sci. 32: 193-207

Mackie, G. O., Bone, Q. (1977). Locomotion and propagation of skin impulse in salps (Tunicata: Thaliacea). Biol. Bull. mar. biol Lab. Woods Hole 153: 180-197

Madin, L. P. (1974). Field observations on the feeding behavior of salps (Tunicata: Thaliacea). Mar Biol. 25: 143-147

Madin, L. P. (1988). Feeding behavior of tentaculate predators: in situ observations and a conceptual model. Bull. mar Sci. 43: 413-429

Madin, L. P. (1990). Aspects of jet propulsion in salps. Can. J Zool. 68: 765-777

Madin, L. P., Cetta, C. M. (1984). The use of gut fluorescence to estimate grazing by oceanic salps. J. Plankton Res. 6 $475-492$

This article was presented by Professor K. Banse, Seattle, Washington, USA
Madin, L. P., Harbison, G. R. (1977). The associations of Amphipoda Hyperiidea with gelatinous zooplankton - I. Association with Salpidae. Deep Sea Res. 24: 449-463

McFall-Ngai, M. J. (1990). Crypsis in the pelagic environment. Am. Zool. 30: 175-188

McLaren, I. A. (1963). Effects of temperature on growth of zooplankton, and the adaptive value of vertical migration. J. Fish. Res. Bd Can. 20: 685-725

McLaren, I. A. (1974). Demographic strategy of vertical migration by a marine copepod. Am. Nat. 108: 91-113

Miller, C. B. (1970). Some environmental consequences of vertical migration in marine zooplankton. Limnol. Oceanogr 15: 727-741

Miller, C. B., SUPER Group (1988). Lower trophic level production dynamics in the oceanic subarctic Pacific Ocean. Bull. Ocean Res. Inst. Univ. Tokyo 26: 1-26

Miller, R. L. (1979). Sperm chemotaxis in the hydromedusae 1 Species-specificity and sperm behavior. Mar. Biol. 53: 99-114

Mills, C. E. (1983). Vertical migration and diel activity patterns of hydromedusae: studies in a large tank. J. Plankton Res. 5: 619-636

Mills, C. E., Goy, J. (1988). In situ observations of the behavior of mesopelagic Solmissus narcomedusae (Cnidaria, Hydrozoa). Bull. mar. Sci. 43: 739-751

Murray, J., Hjort, J. (1912). The depth of the ocean. Macmillan, London.

Neill, W. E. (1990). Induced vertical migration in copepods as a defence against invertebrate predation. Nature, Lond. 345: $524-526$

Ohman, M. D. (1990). The demographic benefits of diel vertical migration by zooplankton. Ecol. Monogr 60: 257-281

Ohman, M. D., Frost, B. W., Cohen, E. B. (1983). Reverse diel vertical migration: an escape from invertebrate predators. Science 220: 1404-1407

Purcell, J. E. (1981). Dietary composition and diel feeding patterns of epipelagic siphonophores. Mar Biol. 65: 83-91

Roman, M. R., Ashton, K. A., Gauzens, A. L. (1988). Day/night differences in the grazing impact of marine copepods. Hydrobiologia 167/168: 21-30

Wiebe, P. H., Madin, L. P., Haury, L. R., Harbison, G. R., Philbin, L. M. (1979). Diel vertical migration by Salpa aspera and its potential for large-scale particulate organic matter transport to the deep-sea. Mar Biol. 53: $249-255$

Wynne-Edwards, L. V (1962). Animal dispersion in relation to social behavior Oliver \& Boyd, Edinburgh

Manuscript first received: September 26, 1990

Revised version accepted: April 19, 1991 